\title{
A relação entre o solo e o Estado - Capítulo I O Estado como organismo ligado ao solo [p. 59]
}

\author{
Friedrich Ratzel
}

Tradução de Matheus Pfrimer*

$1{ }^{1}$ O Estado na geografia e a concepção biogeográfica de Estado. A vida da humanidade sobre a terra se assemelha à de um ser vivo: ela avança, recua, se retrai, engendra novas relações, desfaz os antigos laços; tudo isso segundo imagens que parecem àquelas que são apresentadas pelas outras espécies animais. Imagens como: maré humana, onda humana, ilha humana, ilha política, istmo político, deixam-no entender. Mas, ao utilizálas, não se pensa no sentido profundo que podem ter estas expressões.

Para a biogeografia, elas não são imagens. Há espaços vitais, ilhas de vida, etc. A biogeografia concebe o Estado como forma de extensão da vida sobre a superfície da terra. O Estado sofre as mesmas influências que qualquer vida. As leis de extensão dos homens sobre a terra determinam a extensão dos seus Estados. Quase não se viu a criação de Estados nas regiões polares ou nos desertos, eles continuam a ser pequenos nas regiões tropicais, nas florestas virgens e nas grandes montanhas. Os Estados estenderam-se progressivamente com as espécies humanas; cresceram em número e dimensão com a população. As fronteiras não devem ser concebidas diferentemente do que como a expressão de um movimento orgânico e inorgânico; as formações estatais elementares assemelham-se evidentemente a um tecido celular: em todo lugar se reconhece a semelhança das formas de vida que emergem da ligação com o solo. Para todos, liquens, corais ou homens, esta relação é uma propriedade da vida, porque a condiciona. [p. 60]

O solo favorece ou impede o crescimento dos Estados, como favorece ou impede o movimento dos indivíduos e das famílias. Daí a influência da água sobre o desenvolvimento estatal: os Estados que se estendem naturalmente sobre as margens dos rios ou as costas, prosperam onde a natureza previu um sistema de comunicações, como nas grandes bacias ${ }^{2}$ fluviais. Quanto mais os Estados se aproximam da fronteira do ecúmeno, menos eles são povoados, menos equilibrada é a relação entre a superfície de solo e a população, como é a característica dos Estados montanhosos. Quanto mais afastado do Equador, mais as grandes potências se desenvolvem sobre um espaço estreito, mais o solo fica precioso. Os maiores e mais potentes Estados se encontram nas zonas moderadas, nos países baixos, instalados à vizinhança do mar.

2. O Estado é uma fração de humanidade e uma fração de solo. O homem não é concebível sem o solo terrestre, ainda mais sem a maior obra do homem sobre terra: o Estado. Assim como os termos cidade e estrada expressam, respectivamente, uma fração de humanidade e uma obra humana; quando se fala de Estado, designase uma fração de superfície terrestre. O Estado é obrigado a viver do solo. Ele possui invariavelmente apenas as vantagens oferecidas por um solo que lhe é assegurado. É o que exprime a ciência política quando diz que o território pertence à essência do Estado. Ela designa a soberania como jus territoriale e estabelece a regra que as mudanças territoriais podem fazer-se apenas por leis. A vida dos Estados faz-nos descobrir relações muito mais estreitas: durante a História, vemos as forças políticas se apreenderem do solo e assim levar à formação dos Estados. É por isso que chamo de

\footnotetext{
* Traduzido por Matheus Hoffmann Pfrimer (matheuspfrimer@hotmail.com), doutorando em Geografia Humana pela Faculdade de Filosofia, Letras e Ciências Humanas da Universidade de São Paulo. A tradução foi realizada a partir de RATZEL, Friedrich. La géographie politique: les concepts fondamentaux. Chapitre I - L'État comme organisme lié au sol, Paris: Fayard, 1987, pp. 220, p. 59 - 71.
} 
povo um conjunto político de grupos e indivíduos não necessariamente vinculados pela raça (der Stamm), nem pela língua, mas no espaço, por um solo comum.

Ordens e grupos sociais, comércio e religião extraem desta fonte força política e duração, e tornam-se assim formadores de Estado. Criouse, no século XIX, a ideia nacional. Para muitos, "política nacional" designa uma política fundada sobre a compreensão do valor do solo; dessa forma eles dizem "nacionais" em vez "de territoriais". O sentido político-geográfico da fórmula: os Alemães sentem a necessidade de dar uma forma política à sua comunidade, é que eles [p. 61] procuram se reunir sobre um território determinado, para viver sobre um solo certo, tão vasto possível e que lhes seja conveniente.

3. Assim institui-se a organização política do solo: o Estado constitui-se como organismo ligado a uma fração determinada da superfície da terra, de modo que as suas propriedades se originam das do povo e do solo. As mais importantes são a extensão, a situação e as fronteiras; em seguida vêm o tipo e a forma do solo, com a sua vegetação, a sua irrigação e, por último, as relações que mantêm com o resto da superfície terrestre, e particularmente os mares de interesse político. O conjunto dessas propriedades forma o país (das Land). Mas quando se fala do nosso "país", acrescenta-se o que o homem criou e as lembranças que ali estão enraizadas. De modo que originalmente um conceito apenas geográfico tome o sentido de uma relação espiritual e sentimental entre os habitantes do país e a sua história.

O Estado é um organismo não somente porque articula a vida do povo sobre a fixidez do solo, mas porque esta relação reforça-se por reciprocidade, ao ponto que formam não mais do que um único ser e que não se possa mais pensar em um sem o outro. Solo e povo alcançam esta situação, na medida em que possuem as características necessárias para a ação de um sobre o outro. Um solo inabitável, impotente para alimentar um Estado, é um desperdício histórico. Um solo habitável favorece, pelo contrário, o desenvolvimento do Estado, sobretudo se for limitado de fronteiras naturais. Se um povo encontra-se naturalmente estabelecido sobre o seu território, ele se reproduz constantemente com os caracteres oriundos do solo que se inscrevem e que continuarão a se inscrever nesse povo. Os Gregos, atualmente como na Antiguidade, formam um povo de marinheiros e comerciantes; habitam as ilhas e as franjas costeiras. Os Suíços têm tanto quanto os seus antepassados liberdades cuja sua confederação Ihes permite gozar. É necessário frequentemente esperar o fluxo da onda histórica de modo que um território natural chegue a se valorizar: é o caso da Grécia e a Itália, que, de volta ao seu espaço natural após suas tentativas imperiais, conheceram um novo crescimento, mais limitado, porém mais orgânico. Em muitos casos, o fracasso dos projetos políticos importa pouco, porque os seus germes espirituais, ancorados no seu solo darão continuidade ao seu crescimento: a influência da Grécia no Oriente fazia-se sentir, bem antes Alexandre, pela cultura e pela economia; ela prosseguirá [p. 62] sob a forma do helenismo após a queda do Império de Alexandre. O sentimento de ligação com o solo nunca é tão forte como naqueles lugares onde o solo é bem delimitado, ao ponto de apreendê-lo à primeira vista, e de dominá-lo e explorá-lo facilmente, sobretudo nas ilhas onde a força do nacionalismo dos habitantes exprime-se numa consciência recebida do solo. O desenvolvimento do Estado é a organização progressiva do solo através de uma relação mais estreita com ele. Com o crescimento demográfico, as relações do povo com o seu solo reforçam-se, os recursos naturais sempre são mais bem explorados, o povo cresce em potência até impermeabilizar as fronteiras, como no Baixo Egito, mas por outro lado também aumenta a sua dependência em relação solo. Quanto mais o solo é vasto, mais as suas relações com o povo são tênues. A diferença entre o Estado de um povo civilizado e o de um povo bárbaro se relaciona ao fato de que a organização do solo é muito mais desenvolvida no primeiro do que no segundo. Qualquer apresentação do desenvolvimento do Estado que negligencie o solo está incompleta. Isso vale igualmente para a classificação dos Estados. Vierkandt, por exemplo, distingue os Estados primitivos, construído pelos povos originários, dos 
Estados anárquicos, guerreiros e conquistadores, oriundos de uma formação aristocrata; e é certo que nesta sucessão, a "manifestação crescente de formas fixas que mantêm a personalidade dentro de limites precisos" permite reconhecer a essência do desenvolvimento da civilização. Não é menos verdadeiro que o que se designa nos Estados menos desenvolvidos como "ausência de estrutura" não se relaciona somente à ausência de um exército de ofício, da administração ou tributação, mas depende de uma série de fatores geográficos, e, em especial, da fraqueza da população, de sua desigual distribuição, da falta de ligação com o solo, da imprecisão das fronteiras e a falta de vias de comunicação.

4. Quando se elabora o mapa de um Estado negro, uma imagem simples aparece: a de um organismo elementar. A aldeia do chefe é cercada de aldeias menores, mais adiante uma orla transfronteiriça deserta percorrida por um ou dois caminhos em direção aos territórios vizinhos. Quanta diferença em relação à densidade do tecido apresentado pelo mapa do menor Estado europeu, com os seus pequenos e grandes estabelecimentos, suas capitais e suas cidades fronteiriças, suas fortalezas, sua rede de estradas, os seus canais e os seus caminhos de ferro!

$E$, no entanto, este mapa apresenta apenas esquema de um corpo [p. 63] vivo; não diz nada da ideia política que o anima. Quando o Estado é simples, esta ideia tem apenas um caráter de vontade de dominação; ela é tão efêmera quanto a vida humana. Em um Estado civilizado, é todo o povo que a detêm. A alma dos Estados renovase infatigavelmente através da sequência das gerações. Os Estados mais vigorosos são aqueles onde a ideia política anima o corpo inteiro do Estado. Os membros que não se deixam penetrar pela alma ou pela idéia política se separam, e duas almas dilaceram então a unidade do corpo político.

Dissemos que a política era como o espírito de um Estado ou sua individualidade espiritual. É insuficiente. Na ideia confederalista, da qual povos muito diferentes e Estados fragmentários formaram a Suíça, há muito mais do que apenas a política da confederação. Há também toda a relação dos Suíços com o seu país; e é este fundamento geográfico que fez com que esta idéia política animasse o corpo fraco de uma alma forte.

Quando ocorre a um povo da relação do Estado com seu solo permanecer idêntica durante vários séculos, este princípio inalterado o impregna tão profundamente que não deixa de ser impossível concebê-lo independentemente do seu solo. Pode-se pensar os Holandeses sem a Holanda, os Suíços sem os Alpes, os Montenegrinos sem a montanha negra, e mesmo os Franceses sem a França? Os Atenienses, com o seu pequeno território cujos últimos rincões eram conhecidos e que eles exploravam politicamente desde séculos, podiam compreender a tese de Platão segundo a qual o homem e o Estado se diferenciam apenas em função do seu ambiente. No processo de unificação da Itália, como o da luta sangrenta dos Estados Unidos da América para a sua unidade, há como que uma lei natural que age inconscientemente: o solo que é susceptível de sustentar um Estado pronto e acabado deve cobrir-se de um Estado único que o fará um território unificado. E as ruínas dos lugares santos exprimem a ideia outrora criada, assim como uma fonte submersa sempre jorra novamente. Jerusalém e Roma, Lhassa e Meca podem ter envelhecido, porém elas continuarão eternas.

$\mathrm{Na}$ ideia política, não há não somente o povo, mas também o seu país. É por isso que apenas uma potência política pode progredir sobre um mesmo solo, de maneira a tirar dele todo o seu valor. Os direitos de um Estado sobre o solo de outro destroem a sua independência. Aquilo que uma segunda potência tira de um mesmo solo é perdido pela primeira. Não é como o crescimento de um carvalho que deixa ainda crescer erva sob a sua coroa. [p. 64] O Estado não pode tolerar um terceiro sem se enfraquecer com a presença dele sobre o seu solo.

Assim o antigo Império alemão começou a desfazer-se no momento em que os seus funcionários transformaram os seus domínios em Estados particulares. Na medida em que eles localizavam a sua potência nos territórios que administravam ou os quais herdavam, estes territórios eram perdidos pelo Império. Foi a decomposição: entre o Estado e o seu solo 
nasceram outros Estados; o antigo Império, o velho carvalho, perdeu a sua relação com o solo, as suas raízes ficaram desprotegidas.

Quanto mais a relação do Estado com o seu solo é simples e imediata, mais a sua vida e o seu crescimento são válidos. Sobretudo, é necessário que a maioria da população mantenha uma relação com o solo que faz com que ele seja o seu solo. É isso que dá à economia sua significação do ponto de vista do Estado.

5. A História de um Estado não conseguiria instruir a sua política, não fosse a fixidez do solo. As propriedades do solo agem através das múltiplas modificações dos povos e traduzem-se sob fatos diferentes. O solo é sempre mais velho que o Estado e o seu futuro é muito maior. É por isso que o olhar que se desvia do estado trocando os povos pela consideração do solo ganha em penetração. A península dos Apeninos não podia sempre residir ao centro de um império, ainda mais que ela não podia continuar povoada pela mesma raça; no entanto permaneceu uma das regiões mais importantes do mundo. A geografia política distingue-se da história política pela sua maneira de chamar a atenção às invariantes que têm o solo. Isso permite-lhe apreender o futuro. A política é uma Realpolitik num sentido muito mais verdadeiro que aquela política que não vai além de uma gestão cotidiana, já que ela se propõe a analisar o objetivo último do Estado, se dedicando a garantir ao povo o solo do qual tem necessidade para o seu desenvolvimento.

6. Os limites do orgânico no Estado. Na ordem animal ou vegetal, o organismo mais perfeito é aquele cujas partes sacrificam a sua independência ao serviço do todo. Deste ponto de vista, o Estado permanece um organismo extremamente imperfeito. Os seus membros conservam uma independência que já não se encontra mais nas plantas e nos animais inferiores. O Estado situase no mesmo nível que certas algas ou certas esponjas. Mas o que o [p. 65] torna tão produtivo e tão potente, é que se trata de um organismo espiritual e moral. Uma relação espiritual une o que é materialmente separado. Deste ponto de vista, não há comparação biológica possível. O que governa o organismo Estado, os outros organismos não o conhecem. A evolução dos Estados permite observar de um lado seu enraizamento sobre um solo comum e do outro a fixação espiritual dos habitantes à sua terra em função de um objetivo comum. O pequeno Estado aldeão negro, edificado sobre uma superfície suficiente para sua cultura e defesa, e que não a abandonará a não ser por causa de uma intervenção externa, conhece um crescimento que é quase orgânico. Que venha um chefe carismático ou conquistador, ou que o comércio se ative, o seu crescimento dependerá das forças espirituais. Quanto mais um Estado é desenvolvido, mais tende a livrar-se do seu fundamento orgânico. Ademais, a comparação do Estado com um organismo é ainda mais justa quando se trata de um Estado primitivo, ela é menos justa quando se trata de um Estado desenvolvido.

A comparação do Estado com organismos desenvolvidos não é muito fértil. As numerosas tentativas que foram feitas para tratar o Estado assim como um organismo deram poucos frutos. A causa principal se relaciona ao fato de que nos cegamos com as analogias que podem existir entre o agregado humano e a estrutura de um ser vivo. Adere-se continuamente à prática dessas analogias enquanto que é precisamente deste ponto de vista que surgem as maiores diferenças entre o Estado e um organismo. No Estado, o ser mais individualizado da criação, o homem, não sacrifica nada de essencial ao todo ao qual pertence. Ele pode se retirar dele a qualquer momento. Em contrapartida, num organismo animal as partes estão tão submetidas ao todo que perdem a sua independência. Os elementos que compõem os animais mais perfeitos vivem na maior dependência. Encontra-se o mesmo fenômeno nas sociedades animais: os membros originalmente idênticos são transformados em produtos distintos uns dos outro. Pelo contrário, o Estado mais perfeito é aquele de onde os cidadãos tiram a sua independência do próprio serviço do Estado. 
7. A única base material da unidade do Estado é o solo. Daí a tendência de se fixar sobre ele a organização política, como se ele pudesse forçar os homens sempre divididos a continuar unidos. Quanto mais o Estado corre o risco de dissolverse, mais o solo se torna importante: é o princípio unificador do Estado e a única prova palpável e indestrutível da sua unidade. [p. 66]

A extensão e a forma do Estado, marcadas pelas suas fronteiras, não são dadas de início. Sob a influência do solo, o Estado tende a organizálas. Motivações religiosas e nacionais, lembranças históricas, vontade de potência de um indivíduo, são tantos os princípios formadores dos Estados. Ideias diretoras tomam conta dos espíritos e guiam a vontade dos indivíduos de um determinado território. Enquanto estas ideias diretoras reinarem, reina o Estado.

Quando se deram as suas fronteiras, produziu-se então os processos de troca com o ambiente como o que ocorre na periferia de um organismo complexo. A vida do Estado é feita a partir do ato de união espiritual sobre o seu fundamento material. O Estado é um organismo como o é uma comunidade espiritual. O seu elemento espiritual provém para muitos do solo.

Uma política cuidadosa se comprometerá a não deixar as oposições sociais e econômicas inscrever-se na geografia do Estado a fim de priválas da força que tirariam da sua relação com o solo. É assim que a oposição territorial do norte e o sul dos Estados Unidos é um perigo para a sua unidade. O que foi reconhecido muito cedo e com razão.

8. A relação espiritual com o solo reside no hábito de viver juntos, no trabalho comum e na necessidade de proteção. O hábito de viver juntos torna-se consciência nacional; reúne milhões de homens, do trabalho comum nascem interesses que formam a relação econômica do Estado; quanto à necessidade de proteção, ela dá ao soberano o poder de manter a unidade do Estado. O solo não é somente a cena ou o objeto do trabalho comum, é também a fonte dos frutos do trabalho. $O$ hábito de viver juntos não vincula somente o povo com ele mesmo, mas com o seu solo onde são enterradas as gerações passadas. Daí a sacralização de certos lugares que frequentemente tecem relações muito mais fortes que o único hábito de viver juntos ou o trabalho comum. E da necessidade de proteção deriva a firmeza das fronteiras e o investimento de certos lugares fortes. Assim, esta relação espiritual alimenta-se muito mais do solo que não se pode deixar de pensar no vocabulário impreciso dos historiadores. Das duas "tendências" que os historiadores atribuem à alma do povo grego - "a tendência de ir adiante, a construir cidades, fundar Estados e edificar múltiplas colônias" e, por outro lado, "a tendência a manter-se como nação e a perceber-se diante dos estrangeiros como um só povo" [p. 67] - deve-se explicar a primeira pela instrução geográfica. Não se trata de um impulso interno, mas uma consequência de impressões e de influências externas. É necessário procurar a razão para a segunda tendência no fechamento dos territórios, no caráter urbano destes territórios que já consolidam o sentimento nacional. Ao contrário, "o impulso ao Estado", do qual se diz que não pertence à alma fenícia, enquanto que a encontramos geralmente nos indo-germânicos, diz respeito a relações diferentes das que essas duas comunidades, uma agrícola, e outra comercial, mantinham com o solo.

9. Os elementos últimos do organismo estatal são os grupos sociais. É apenas excepcionalmente que os indivíduos têm uma importância para o Estado. É muito raro que os indivíduos sejam soberanos e proprietários do solo do Estado. São geralmente famílias, clãs, comunidades aldeãs, grupos de imigrantes, confrarias, organizações militares, sociedades comerciais, ordens religiosas que apropriam-se e trabalham o solo no âmbito do Estado e para ele. O mais importante destes grupos é a família, união natural de um homem, de uma mulher e de sua prole, pouco importa que seja monógama ou polígama, estende-se aos avós e netos, aos colaterais, aos escravos, seja ela governada por um direito matriarcal ou patriarcal. A família possui uma propriedade decisiva: permite a acumulação de conhecimentos e experiências através da renovação das gerações; além disso, é o agente do crescimento demográfico. 
A questão essencial para um povo ou um Estado é a conservação do lar. É excepcional que povos chegam a se manter por muito tempo a partir do rapto ou compra de crianças. Os Djaggas, povo conquistador que abalou anteriormente a África interna, matavam as suas próprias crianças e recrutava escravos. Os ribeirinhos de San Cristobal (ilhas Salomão) enterravam vivos os recém nascidos e compravam as suas crianças de pequenos homens que viviam nas florestas no interior da ilha.

A família funda o princípio da sua coesão sobre o amor sexual e materno da mulher. Ao lado dela se juntam as confrarias que encontram a sua coesão no instinto de sociabilidade. Ainda que estas sociedades não tenham a mesma importância que a família para a vida de um povo, isso não significa que elas não desempenhem um papel decisivo menor: seja porque se opera uma divisão do trabalho social e político de acordo com as idades, os [p. 68] jovens belicosos e conquistadores formam grupos de caçadores e de guerreiros enquanto que idosos experientes e conservadores estão a cargo do governo; seja porque constituídas em sociedades secretas, elas guardam e transmitem tradições, se constituem em centro político e religioso e resistem às tendências que têm as famílias de se isolar ao se agrupar em confederações nacionais (Heinrich Schurtz). Inclusive, não é raro que estas associações tenham desorganizado o crescimento natural ao enfraquecer a vida em família.

Mas a intensificação do comércio, das trocas e da circulação não tardou a fazer prevalecer sobre a diversidade das formações familiares e sociais, certa uniformidade de estrutura.

\section{A formação de órgãos pelo Estado} necessariamente é limitada. Um organismo diferencia-se de um agregado pela divisão de trabalho que é responsável pela criação de órgãos. O organismo estatal apresenta esta particularidade que pode alterar os seus elementos apenas de maneira muito restrita. No seu caso, o motivo mais importante da formação de órgãos se relaciona às diferenças territoriais e na repartição espacial da população. Razão pela qual se observa, antes de tudo, as grandes oposições entre as zonas periféricas e centrais, costas e interior, planícies e montanha, cidades e campo, zonas com forte e fraca densidade demográfica. As diferenças históricas que atravessam um Estado têm frequentemente este fundamento geográfico. A oposição entre os novos e os velhos estados dos Estados Unidos da América coincide evidentemente com a oposição entre zona atlântica e pacífica, leste-oeste, húmida-seca, povoada-despovoada. Já se observou que as diferenças internas dos povos e dos Estados tomam a sua importância apenas quando se fazem registrar na geografia.

11. Certas partes de um organismo são mais estritamente ligadas à vida do ponto de vista do todo do que outras. São sempre as partes vitais e geograficamente as mais importantes do Estado. É necessário localizar a posição delas no organismo para apreciar o seu valor político. Qualquer Estado tem regiões ou províncias cuja perda Ihe seria mortal, enquanto que outras ele pode abandonar sem perigo. As partes vitais são certamente onde se situam as grandes vias de comunicação. Um grande país não pode se privar das zonas costeiras, ou das vias fluviais ligando ao mar. A embocadura de um [p. 69] rio é indispensável, enquanto que o seu curso médio pode ser substituído por uma ferrovia. As zonas vitais se valorizam com o progresso da civilização, as outras podem sofrer uma desvalorização provisória. Afastada e distante do Danúbio, a Sérvia seria definitivamente mutilada. É por isso que ela se concentra fortemente em Belgrado. A Suíça é inconcebível sem as suas fronteiras alpinas, ao passo que ela poderia esta numa situação melhor se privando das suas colinas do Trans-Reno e Jura.

O valor de uma parte do Estado depende da sua relação geográfica com o todo do organismo estatal. Os elementos geográficos de um país que agem no sentido da sua propriedade essencial possuem a maior importância porque se adicionam a uma soma de vantagens presentes. Para a península ibérica, os Pirineus têm a sua importância que a fazem quase uma ilha. Para a Itália, o Pó, reforçando o seu caráter insular, teve na Antiguidade a mesma importância que os Alpes 
nos tempos modernos. Uma costa escarpada, susceptível de proteger numerosos portos, reforça as vantagens de uma situação insular. Para um país cujo desenvolvimento seria, sobretudo, continental, isso não teria de forma alguma a mesma importância. Quando tais regiões vêm se associar a um Estado, a sua importância política cresce normalmente. Contrariamente, uma decisão política pode vir mutilar o que a natureza uniu.

12. A esfera econômica tende à organicidade. A vida política de um Estado consiste em instituir órgãos. Mas a vida econômica que dependente do clima e das características do território, não dá o mesmo valor às diferentes regiões de um país. Se um Estado tem necessidade de uma região pelo seu trigo, de outra pela sua madeira, estas regiões tornam-se órgãos do organismo econômico. A sua unidade é ainda mais forte que estes territórios recebem vantagens no pertencimento a este organismo. Se ele acaba por perder uma, o todo se mutila e se individualiza. A posição do Egito no Império Romano permanece o exemplo típico de um território completamente reduzido à posição de órgão.

13. Há na própria terra limites necessários para a formação de órgãos. Mesmo no caso do organismo econômico, as propriedades naturais da terra contradizem a tendência à constituição de órgãos. A semelhança dos homens sobre vastos espaços age no mesmo sentido. Ela proíbe que se considere países e [p. 70] povos como simples engrenagens de uma máquina. A repressão do artesanato nas colônias onde a metrópole quer forçar a especialização na agricultura e na criação de animais não pode ter êxito por muito tempo. Ainda mais causando a obstrução das trocas comerciais naturais em proveito da metrópole. A Espanha perdeu o seu império colonial americano por esta razão; a Dinamarca renunciou à Islândia por uma razão análoga. O fechamento de Antuérpia pela Holanda, quando do tratado de Westfália, criou uma situação inorgânica prejudicial e sem futuro. Ainda menos suportável era o bloco da Bélgica quando da ocupação pelos holandeses de todos os nós rodoviários e fluviais importantes. A
Inglaterra hoje é confrontada pela dificuldade de conter o desenvolvimento da indústria e o comércio da Índia povoada em excesso.

Qualquer comunidade humana luta com o exterior e si própria para assegurar-se uma vida independente. Ela quer permanecer um organismo; mas o trabalho incessante do: "Morrer e renascer", que é realizado pela História, tende a reduzi-lo à condição de órgão. Observa-se incessantemente a integração das existências autônomas em grandes agrupamentos; elas apenas raramente são substituídas por novos entes. Há atualmente cinqüenta e quatro Estados independentes, enquanto que havia vários milhares deles há alguns séculos. O comércio internacional trabalha para transformar a terra inteira num vasto organismo econômico onde povos e países são mais que órgãos subordinados. Quanto do fluxo do comércio internacional já não se dirige para Londres? É necessária toda a energia e a perseverança de um povo para se opor a este movimento que centraliza de modo a continuar cultural e politicamente independentes.

Num organismo como o Estado, constituído de elementos também semelhantes, a relação das partes entre si (correlação) tem muito mais importância do que quando o organismo tem órgãos determinados. A sua estrutura, feita de elementos análogos a um órgão central predominante, é simples. Nós veremos que o comércio é o artesão mais importante destas relações.

Ele se vincula ao caráter orgânico do Estado que se mensura e se eleva como um todo. O crescimento dos seus elementos é também um crescimento para o todo. Qualquer vantagem adquirida num domínio se aproveita aos outros e se acrescenta àquelas vantagens que resultam do solo, da população, das riquezas e das possibilidades. Isso não seria possível se o Estado fosse apenas o Universitas agrorum intra fines cujus civitatis ${ }^{3}$, como o caracteriza uma pobre definição. Ainda que as [p. 71] estradas, as fronteiras e as fortificações não fossem propriedade coletiva, qualquer infração levada ao todo é sentida por cada lar como um prejuízo pessoal, enquanto que a plenitude do todo incumbe a cada um. Nos estados modernos, este sentimento comunitário toma um caráter territorial tão forte que a menor infração levada ao território 


\section{Notas:}

${ }^{1}$ Os números remetem aos parágrafos da edição original alemã.

2 N. T. o autor empregou o termo região. Tratase de uma tradição da geografia alemã deste período caracterizar a região a partir das bacias hidrográficas.

3 N. T. A frase latina acima se refere ao pronunciamento do Imperador romano Constantino que afirma que o território é a universalidade das terras dentro dos limites de cada Estado; alguns o chamam assim porque o magistrado desse lugar tem o direito de, dentro destas terras, aterrorizar, isto é, de afugentar - "Territorium est universitas agrorum intra fines cuiusque civitatis quod ab co dictum quidam aiunt quod magistratus eius loci intra eos fines terrendi, id est, submovendi ius habet." 